\title{
A test for successive incentive contrast effects with a highly preferred fluid reward
}

\author{
W. MILES COX \\ Richard L. Roudebush Veterans Administration Medical Center \\ Indiana University School of Medicine, Indianapolis, Indiana
}

and

JOHN E. MERTZ

University of Illinois, Urbana, Illinois

\begin{abstract}
Forty albino rats were tested in a successive incentive effects experiment with water and near beer as fluid rewards. During Phase 1, there were no differences in goal speeds between groups receiving water and those receiving near beer. The group that was shifted from water to near beer did not run faster during Phase 2 than the group that was always given near beer. The group that was shifted from near beer to water did not run slower during Phase 2 than the group that was always given water. These results are surprising in view of the fact that in a previous study near beer had been found to be highly preferred over water.
\end{abstract}

Successive shifts from a more to a less attractive reward have consistently resulted in negative contrast effects, but shifts from a less to a more attractive reward have resulted in positive contrast effects only in special circumstances (Cox, 1975). For example, when reward is delayed, Mellgren $(1971,1972)$ reported positive contrast effects with successive upshifts in magnitude of food reward.

In the present experiment, using a fluid-near beerthat we earlier had identified as being strongly preferred by rats (Cox $\&$ Mertz, 1985), we studied successive shifts in the quality of fluid rewards. To humans, near beer is indistinguishable in taste from regular beer (Cox \& Klinger, 1983) but contains negligible amounts of alcohol. Hence, it provides the opportunity for studying beer taste preferences apart from reactivity to ethanol. In the Cox and Mertz (1985) study, animals showed an overwhelming preference for near beer over both water and beer containing $3.2 \%$ alcohol. In fact, the volume of near beer consumed ad lib was several times the volume of water consumed during baseline. From these results, it appeared that near beer would be a potent reinforcer, and it seemed that shifts from a less preferred fluid to near beer, or vice versa, would provide the circumstances for incentive contrast effects to occur. In particular, we were interested in determining if an upshift to such an attractive fluid as near beer would result in a positive contrast effect.

The authors thank Ernest D. Kemble for his comments on the mauscript. J. E. Mertz is associated with the Department of Chemistry at the University of Illinois. Requests for reprints should be sent to W. M. Cox, Psychology Service (116B), Veterans Administration Medical Center, 1481 West 10th Street, Indianapolis, IN 46202.

\section{METHOD}

\section{Subjects}

The subjects were 40 female albino rats, purchased from the Holtzman Company of Madison, Wisconsin, and approximately 90 days old at the beginning of training.

\section{Apparatus}

The apparatus was a single straight runway that was painted flat gray and had clear Plexiglas ceilings. The interior was $10 \mathrm{~cm}$ wide and $119 \mathrm{~cm}$ long, and the startbox, alley, and goalbox were $25.5,63$, and $30.5 \mathrm{~cm}$ long, respectively. Guillotine doors separated the startbox and the goalbox from the alley. A caster cup was placed at the end of the goalbox for fluid reward. Response latencies were measured with photoelectric circuitry. Run and goal times were measured over distances of 51 and $30 \mathrm{~cm}$, respectively.

\section{Procedure}

Upon receipt from the supplier, the animals were housed in individual home cages, where they were given ad-lib access to food and water. The animals continued to have ad-lib access to food throughout the experiment, but 5 days prior to experimental training, fluid deprivation was initiated and continued until the conclusion of the experiment. The regimen consisted of exposing the animals to tap water for 30 min daily.

Four groups, consisting of 10 animals each, were run. For its reward in the runway, one experimental group was given water during Phase 1 and was shifted to near beer during Phase 2. The other experimental group was given near beer during Phase 1 and was shifted to water during Phase 2. One control group received water during both the pre- and postshift phases, and the other control group received near beer during both phases. The near beer was Schmidt Select.

One day prior to the beginning of training, the animals explored the runway for $5 \mathrm{~min}$ in groups of 5 animals. During training, the animals were tested in squads of 10 animals each in a dimly illuminated experimental room. Each animal was placed in the runway such that it faced away from the startbox door, and as soon as it had oriented toward the door, the door was opened to permit traversal of the alley. When the animal had entered the goalbox, the goalbox door was closed to prevent reentry into the alley. Each animal was allowed to consume its fluid (carbonated near beer or water) from the goal cup for $20 \mathrm{sec}$, after which it was returned to its carrying cage to await the next trial. All animals 


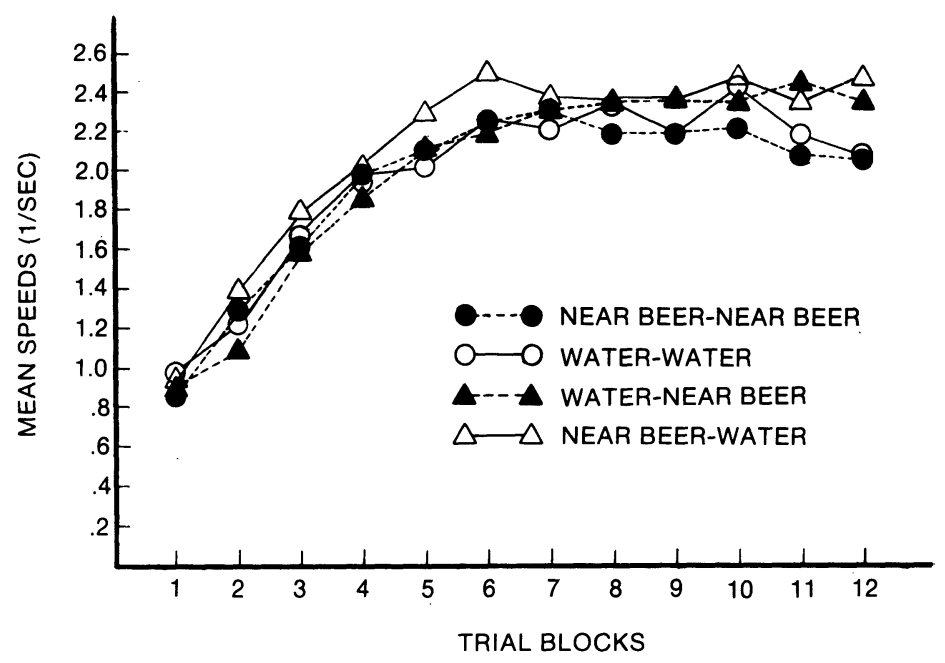

Figure 1. Mean goal speeds of the four groups during Phase 1.

received four daily trials, with an intertrial interval of about $15 \mathrm{~min}$. When each squad's daily trials had been completed, the animals were returned to their home cages and given access to tap water for $30 \mathrm{~min}$.

\section{RESULTS AND DISCUSSION}

Prior to analysis, latencies were converted into speeds (1/sec.), and each animal's four daily trials were averaged. Run and goal speeds are similar, and only the latter are shown here. In Figure 1, we see that the four groups showed typical conditioning curves and appear to have stabilized by the conclusion of Phase 1 . However, no group differences are apparent. Analysis of variance performed on the data from Phase 1 confirmed that there was no effect for groups $(F<1.0)$ or interaction of groups and days $(\mathrm{F}<1.0)$, but that there was a significant effect for days $[F(11,396)=75.65, \mathrm{p}<.001]$.
Goal speeds from Phase 2 are shown in Figure 2. Here we see some random fluctuations in performance across days, but for the most part the groups performed at the level they had attained at the conclusion of Phase 1 . Clearly, there was no tendency for the group that had been shifted from near beer to water to undershoot the performance of the group that had been given water during both phases. Figure 2 suggests, on the other hand, that throughout Phase 2 the group that had been shifted from water to near beer ran more rapidly than its control group, which had received near beer during both phases. However, inspection of Figure 1 indicates that by the conclusion of Phase 1 the former group also ran more rapidly than the latter group, suggesting that the apparent difference in the speeds of these two groups during Phase 2 reflects sampling error. In fact, statistical analysis of the data from Phase 2 indicates that although the fluctuations in speeds

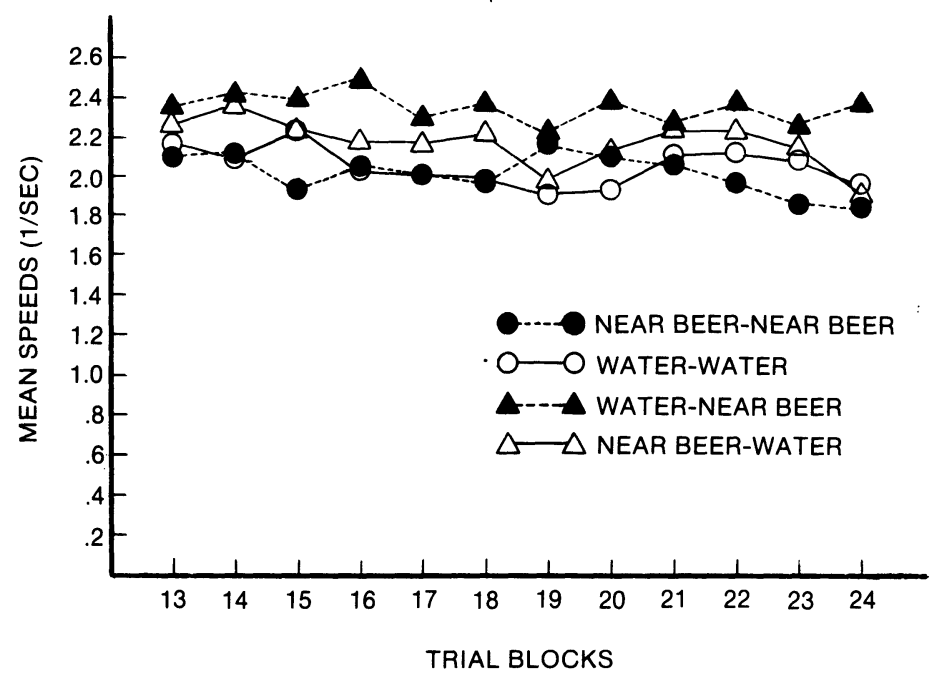

Figure 2. Mean goal speeds of the four groups during Phase 2. 
across days were statistically significant $[\mathrm{F}(11,396)=$ $2.09, \mathrm{p}<.02]$, there was no effect for groups $(\mathrm{F}<1.0)$ and no groups $\times$ days interaction $(F<1.0)$.

Considering the magnitude of the animals' preference for near beer over water in the Cox and Mertz (1985) study and the far greater volume of near beer than water that they consumed, it is surprising that the animals in the present experiment did not run at different speeds for water and near beer and did not show contrast effects with shifts between water and near beer. Nevertheless, the present results are consistent with those from other studies that have failed to find successive contrast effects with qualitative shifts in reward (see Mackintosh, 1974, pp. 391-393).

Other training procedures, however, including the discrete-trails simultaneous contrast effects paradigm and various free-responding techniques, have obtained contrast effects with shifts in quality of reward. Hence, near beer should be studied in a variety of other situations to assess further its reinforcing properties.

One variable that might be fruitful for future research is the degree of animals' familiarity with near beer when it is introduced as a reinforcer. In the Cox and Mertz (1985) study, even though the animals showed an immediate strong preference for near beer, the 12-h exposure intervals in that study greatly increased the animals' familiarity with near beer over what it was in the present study. Perhaps greater preexperimental exposure would maximize the chances for the reinforcing properties of near beer to become manifest.

Another variable to consider in future studies is the effect of severe water deprivation on the reinforcing value of near beer. Although rats might strongly prefer the taste of near beer over water, near beer might be less thirst quenching than water when rats are fluid deprived for $23.5 \mathrm{~h}$. Food deprivation (which invariably involves some water deprivation as well) may maximize rats' reactivity to near beer in future experiments.

\section{REFERENCES}

Cox, W. M. (1975). A review of recent incentive contrast studies involving discrete trial procedure. Psychological Record, 25, 373-393.

Cox, W. M., \& KLINGER, E. (1983). Discriminability of regular, light, and alcoholic and nonalcoholic near beer. Journal of Studies on Alcohol, 44, 494-498.

Cox, W M., \& MERTZ, J. E. (in press). Do rats prefer water, near beer, or beer with ethanol? Bulletin of the Psychonomic Society.

Mackintosh, N. J. (1974). The psychology of animal learning. London: Academic Press.

Mellgren, R. L. (1971). Positive contrast in the rat as a function of the number of preshift trials in the runway. Journal of Comparative and Physiological Psychology, 77, 329-336.

Mellgren, R. L. (1972). Positive and negative contrast effects using delayed reinforcement. Learning and Motivation, 3, 185-193.

(Manuscript received for publication August 6, 1984.) 